BMJ

Open

Gastroenterology

\section{A Retrospective Analysis of COVID-19- infected Patients with Acute Hepatitis who Develop Acute Liver Failure in a Safety Net Hospital}

To cite: Pellegrini Jr. JR, Sabbula B, Russe-Russe JR, et al. A Retrospective Analysis of COVID-19infected Patients with Acute Hepatitis who Develop Acute Liver Failure in a Safety Net Hospital. BMJ Open Gastro 2021;8:e000738. doi:10.1136/ bmjgast-2021-000738

Received 6 July 2021 Accepted 25 October 2021
Check for updates

\section{(C) Author(s) (or their} employer(s)) 2021. Re-use permitted under CC BY-NC. No commercial re-use. See rights and permissions. Published by BMJ.

${ }^{1}$ Internal Medicine, Nassau University Medical Center, East Meadow, New York, USA

${ }^{2}$ Pulmonary \& Critical Care, Nassau University Medical Center, East Meadow, New York, USA

${ }^{3}$ Surgery, Nassau University Medical Center, East Meadow, New York, USA

Correspondence to Dr James Robert Pellegrini Jr.; pellegrinij3@gmail.com

\section{ABSTRACT}

Objective In early 2019, a new coronavirus called SARSCoV-2 emerged and changed the course of civilization. Our study aims to analyze the association between acute liver failure (ALF) and mortality in patients infected with COVID-19. A retrospective analysis of 864 COVID-19infected patients admitted to Nassau University Medical Center in New York was performed.

Design ALF is identified by acute liver injury (elevations in liver enzymes), hepatic encephalopathy and an international normalised ratio greater than or equal to 1.5 . These parameters were analysed via daily blood work and clinical assessment. Multivariate logistic regression model predicting mortality and controlling for confounders such as age, coronary artery disease, intubation, hypertension, diabetes mellitus and acute kidney injury were used to determine the association of ALF with mortality.

Results A total of 624 patients, out of the initial 864, met the inclusion criteria-having acute hepatitis and COVID-19 infection. Of those 624, 43 (6.9\%) patients developed ALF during the course of their hospitalisation and their mortality rate was $74.4 \%$. The majority of patients with ALF were male (60.6\%). The logistic model predicting death and controlling for confounders shows COVID-19 patients with ALF had a nearly four-fold higher odds of death in comparison to those without ALF $(p=0.0063)$.

Conclusions Findings from this study suggest that there is a significant association between mortality and the presence of ALF in patients infected with COVID-19. Further investigation into patients with COVID-19 and ALF can lead to enhanced treatment regimens and risk stratification tools, which can ultimately improve mortality rates during these arduous times.

\section{INTRODUCTION}

In early 2019, a new coronavirus called SARSCoV-2, emerged and changed the course of civilization. According to the Centers for Disease Control and Prevention, to date, there have been over 33 million confirmed cases and over 600,000 deaths related to
Summary box

What is already known about this subject?

- COVID-19-infected patients have presented with extrapulmonary manifestations, with the liver being an organ of interest. Little is known about the impact of COVID-19 on the liver and associated outcomes.

What are the new findings?

- Our study found that patients with COVID-19 infection and acute hepatitis who progressed to acute liver failure had a nearly fourfold higher odds of death than those with COVID-19 infection and without acute liver failure.

How might it impact on clinical practice in the foreseeable future?

- This new finding may impact clinical practice by aiding physicians' ability to formulate risk stratification tools early in the disease process and enhancing treatment regimens, ultimately improving mortality rates.

COVID-19 in the United States of America (USA). ${ }^{1}$

Nassau County in the state of New York had some of the first confirmed cases in the USA. Nassau University Medical Center, a 19-story hospital with over 500 beds, started admitting COVID-19 infected patients at the beginning of March 2020. ${ }^{2}$ COVID-19 typically presents with fever, cough and dyspnea within 2-14 days after exposure. ${ }^{3}$ It also has the potential to cause acute respiratory distress syndrome (ARDS), acute kidney injury (AKI) and liver damage. ${ }^{4}$ Liver biopsies of patients with COVID-19 have been found to be positive for viral RNA indicating that liver injury may be a direct consequence of the virus. ${ }^{5}$ This link led to further investigation of acute liver failure (ALF), a severe life-threatening form of liver injury. Our study aims to analyze 
the association between ALF and mortality in patients infected with COVID-19 and acute hepatitis.

\section{METHODS}

We performed a retrospective analysis of patients admitted to our tertiary care centre at Nassau University Medical Center with a diagnosis of COVID-19 infection from March 2020 to May 2020. ALF was identified by acute liver injury (shown by elevations in liver enzymesaspartate aminotransferase (AST), alanine aminotransferase (ALT), and/or alkaline phosphatase (ALP)), hepatic encephalopathy and an international normalized ratio (INR) greater than 1.5. These parameters were analyzed via daily blood work and clinical assessments. Patients who were intubated and sedated were placed on sedation vacations daily and then had their mental status reassessed during that time. The absence of existing liver disease distinguishes ALF from decompensated cirrhosis or acute-on-chronic liver failure. ${ }^{6} 7$ Patients transferred to another acute care facility, history of chronic liver disease and those who died on the day of admission were excluded from the study. Data were collected on age, sex, race, comorbid conditions (diabetes mellitus (DM), coronary artery disease (CAD), hypertension (HTN)), liver enzyme levels, INR levels, documentation of signs of encephalopathy using West Haven criteria, need for mechanical ventilation (implying respiratory failure) and inpatient mortality rates.

Descriptive statistics are presented as mean $\pm \mathrm{SD}$, or as numbers and percentages. Student t-test and $\chi^{2}$ test were used to compare categorical and continuous variables, respectively. Wilcoxon rank sum test was used to compare two groups of non-parametric data. The in-hospital mortality rates were compared between ALF and non-ALF groups using chi square test. A multivariate logistic regression predicting mortality controlling for confounders such as age, CAD, intubation, HTN and DM type 2, and AKI were employed to determine the significance of ALF. Statistical significance was defined as $\mathrm{p}<0.05$. All statistical analysis was performed using SAS V.9.4 by SAS Institute.

\section{RESULTS}

A total of 864 patients infected with COVID-19 were analyzed for this study. A total of 624 patients, out of the initial 864, met the inclusion criteria-having acute hepatitis and COVID-19 infection.

Out of the 624 COVID-19-infected patients, 43 (6.9\%) developed ALF during the course of their hospitalization with a mortality rate of $74.4 \%$ compared with 182 $(31.3 \%)$ who expired without ALF, $(\mathrm{p}<0.0001)$ (table 1$)$. The majority of the patients with ALF consisted of males, which constituted $60 \%$ of the ALF group. A total of 145 patients were found to be intubated, and of those 145 , $126(86.9 \%)$ expired. On the other hand, 479 patients were not intubated, and $81.6 \%$ of these patients survived $(\mathrm{p}<0.0001)$ (table 1). Diabetics was found to have a higher mortality rate, with $42 \%$ expiring compared with $29.1 \%$ of non-diabetic $(\mathrm{p}=0.0009)$ (table 1$)$. Patients with HTN also

Table 1 Comparison of COVID-19 patient characteristics between alive and expired

\begin{tabular}{|c|c|c|c|c|}
\hline & & COVID-19 c & udy & \\
\hline & & $\begin{array}{l}\text { Alive } \\
\text { ( } n=410)\end{array}$ & $\begin{array}{l}\text { Expired } \\
(n=214)\end{array}$ & $P$ value \\
\hline Age, mean+SD (median) & Years & $58 \pm 15.0(57)$ & $69.8 \pm 14.3(69)$ & $<0.0001$ \\
\hline Sex, n (\%) & Male & $249(65.9)$ & $129(34.1)$ & 0.9128 \\
\hline & Female & $161(65.5)$ & $85(34.6)$ & \\
\hline Acute liver failure, $\mathrm{n}(\%)$ & Yes & $11(25.6)$ & $32(74.4)$ & $<0.0001$ \\
\hline & No & $399(68.7)$ & 182 (31.3) & \\
\hline Intubated, n (\%) & Yes & $19(13.1)$ & 126 (86.9) & $<0.0001$ \\
\hline & No & $391(81.6)$ & $88(18.4)$ & \\
\hline Diabetes, n (\%) & Yes & $145(58.0)$ & 105 (42.0) & 0.0009 \\
\hline & No & $265(70.1)$ & $109(29.1)$ & \\
\hline Hypertension, n (\%) & Yes & $227(61.4)$ & $143(38.7)$ & 0.0057 \\
\hline & No & $183(72.1)$ & $71(28.0)$ & \\
\hline Coronary artery disease, n (\%) & Yes & $37(45.1)$ & $45(54.9)$ & $<0.0001$ \\
\hline & No & $373(68.8)$ & $169(31.2)$ & \\
\hline Acute kidney injury & Yes & $40(24.1)$ & $126(75.9)$ & $<0.0001$ \\
\hline & No & $370(80.8)$ & $88(19.21$ & \\
\hline
\end{tabular}

$\chi^{2}$ test.

Bold: $\mathrm{p}<0.05$.

*Wilcoxon rank sum test, mean and SD shown for illustrative purposes only. 
Table 2 Logistic regression predicting death; estimates in ORs with $\mathrm{Cls}$

\begin{tabular}{|c|c|c|c|}
\hline Effect & $\begin{array}{l}\text { OR } \\
\text { estimates }\end{array}$ & $\begin{array}{l}95 \% \text { confidence } \\
\text { Limits }\end{array}$ & $P$ value \\
\hline Age & 1.50 & 1.35 to 1.67 & $<0.0 .0001$ \\
\hline $\begin{array}{l}\text { Acute liver } \\
\text { failure }\end{array}$ & 3.75 & 1.48 to 9.96 & 0.0063 \\
\hline $\begin{array}{l}\text { Coronary artery } \\
\text { disease }\end{array}$ & 1.48 & 0.76 to 2.85 & 0.2474 \\
\hline Intubated & 28.83 & 15.21 to 57.52 & $<0.0001$ \\
\hline Hypertension & 0.37 & 0.19 to 0.68 & 0.0016 \\
\hline $\begin{array}{l}\text { Diabetes } \\
\text { mellitus }\end{array}$ & 1.21 & 0.71 to 2.06 & 0.4780 \\
\hline $\begin{array}{l}\text { Acute kidney } \\
\text { injury }\end{array}$ & 4.78 & 2.73 to 8.44 & $<0.0001$ \\
\hline
\end{tabular}

had higher mortality rates when compared with patients without HTN (38.7\% vs 28\%, respectively; $\mathrm{p}=0.0057)$,) and patients with AKI had a higher mortality compared with those without $(75.9 \%$ vs $24.10 \%, \mathrm{p}<0.0001)$ (table 1$)$. $54.9 \%$ of patients with CAD expired, as opposed to only $31.2 \%$ of patients without CAD $(\mathrm{p}<0.0001)$ (table 1$)$.

The logistic model predicting death and controlling for age, CAD, intubation, HTN, DM and AKI, shows COVID-19 patients with ALF had nearly fourfold higher odds of death in comparison to those who did not have ALF (95\% CI 1.48 to $9.96, p=0.0063$ ) (table 2 ). Furthermore, intubated patients had a 29-fold increased odds of death $(95 \%$ CI 15.21 to $57.52, \mathrm{p}<0.0001)$ and AKI had an OR of death of 4.78 (95\% CI 2.73 to $8.44, \mathrm{p}<0.0001)$ (table 2).

\section{DISCUSSION}

As a novel virus, the clinical manifestations of COVID-19 remain incompletely understood. COVID-19 predominantly presents with a pulmonary syndrome; however, more attention is being paid to extrapulmonary organ involvement due to its significant contribution to morbidity and mortality. Many organ systems have been shown to be involved in COVID-19, including the cardiovascular, gastrointestinal, renal and central nervous systems. $^{3}$

Several studies have shown different levels of elevated liver enzymes in COVID-19 patients, characterized by elevations in ALT, AST and ALP, accompanied by mildly elevated total bilirubin. ${ }^{89}$ Mandal et al found 15\%-20\% of patients hospitalized with COVID-19 had elevated liver enzymes. ${ }^{10}$ To this day, it remains unclear whether these elevated laboratory tests are associated with worsening prognosis.

A major contributor to the extrapulmonary insult seen in severe COVID-19 cases is the generalised hyperinflammatory state; however, direct infection of extrapulmonary tissues has also been demonstrated. ${ }^{11}$ The extensive tissue tropism of COVID-19 has been attributed to broad
ACE-2 expression in a variety of cell types, which the virus uses for host cell entry. ${ }^{11-13}$ Notably, hepatocytes and cholangiocytes have been shown to express the ACE-2 receptor, making them susceptible to infection. ${ }^{12-14}$ Some COVID-19 liver biopsies have demonstrated elevated mitotic errors, ballooning degeneration of hepatocytes and SARS-CoV specific protein 7a via caspase-dependent pathways. ${ }^{15} 16$ In response, increased activity of hepatocytes and cholangiocytes in response to hypoxemia may further enable invasion of COVID-19, therefore, propagating liver injury. ${ }^{17} 18$ This detrimental cycle may be explained by the fact that cholangiocytes are crucial for liver regeneration and immune response in liver injury, furthermore a recent single-cell RNA sequencing analysis of cell-specific ACE-2 expression found that up to $60 \%$ of cholangiocytes and 2.6\% of hepatocytes expressed ACE-2 receptors that when bound to COVID-19 dysregulates liver function. ${ }^{19}$ One study showed an acute hepatitis superimposed on acute cellular rejection with significant bile duct injury. ${ }^{11}$ In situ hybridization of that study identified SARS-CoV-2 viral RNA in rare cells and electron microscopy showed viral particles within cells. ${ }^{11} 162021$ This suggests that SARS-CoV-2 may induce programmed death in hepatocytes. It is well documented that several systemic viral infections including Epstein-Barr virus, cytomegalovirus, herpes simplex virus, parvovirus and adenovirus are associated with similar elevations of liver enzymes reflecting inflammation and immune response by circulating proinflammatory cytokines. ${ }^{15}$

Although ALF may be induced by multiorgan failure, we suggest that a cytokine storm has more influence in producing ALF and affecting other organs thereby producing multi-organ failure. In other words, after COVID-19 infection, CD4 + T cells activate and become $\mathrm{T}$ helper-1 cells which produce an increase of inflammatory cytokines, such as interleukin (IL)-2, IL-7, interferon- $\gamma$ and tumour necrosis factor- $\alpha$ which in turn induces high expression of IL- 6 by CD14+/CD16 + monocytes accelerating inflammation, hence cytokine storm. ${ }^{20}$ When the cytokine storm begins, circulating lymphocytes migrate to the liver further propagating liver injury. This cytokine storm is responsible for producing multiorgan failure, defined as failure of at least 2 of the following organs; liver, lung and kidneys. However, recent studies suggest that after the lungs, the liver is the second organ mainly affected by COVID-19. ${ }^{22}$ Therefore, when the liver fails due to COVID-19 infection, by definition, it induces multiorgan failure. Once multiorgan failure occurs the overall prognosis worsens as there is a significant association between mortality and ALF in patients with COVID19 , as demonstrated by our study.

Other studies suggest that liver damage may be secondary to drugs, since these patients were treated with drugs known to cause hepatic injury such as antivirals, antibiotics, antipyretics and analgesics. ${ }^{15}$ Two common drugs used during the time period of our study that could cause hepatotoxicity were Hydroxychloroquine and Remdesivir. However, at our institution patients 
only received Hydroxychloroquine, making them less susceptible to DILI. Limited COVID-19 autopsies showed histological samples with microvesicular steatosis, mild lobular and portal activity, mild sinusoidal dilatation, and minimal lymphocytic infiltration, indicating cellular injury. ${ }^{15}$ These non-specific changes may be caused directly by SARS-CoV-2 infection, hypoperfusion due to systemic response, and/or drug-induced liver injury.

While there is a growing body of literature on the hepatic manifestations of COVID-19, the contribution of COVID-19-induced hepatitis (and specifically its most severe form in ALF) remain incompletely understood and unquantified. ${ }^{16}$ Our study highlights the importance of hepatic dysfunction and prognosis in patients with COVID-19. We found that patients with COVID-19 and acute hepatitis, who ultimately progressed to ALF had a nearly fourfold higher odds of death, controlling for other factors. Hepatic dysfunction may be an important factor to consider when developing risk stratification tools or methods, as the scientific community, clinical or otherwise, begins to characterize the full effects of COVID-19. Coincidentally, our study also demonstrated that the coexistence of comorbidities such as diabetes, HTN and CAD were statistically significant to the development and deterioration of ALF contributing to the morbidity and mortality of the population studied. Whether certain at-risk groups can be identified sooner, and whether such identification would alter the treatment or therapeutics offered is still an area of further investigation.

\section{CONCLUSION}

Findings from this study suggest that there is a significant association between mortality and the presence of ALF in patients infected with COVID-19. As such, clinicians should remain vigilant of ALF while managing patients with COVID-19 due to its drastic adverse impact on prognosis. Further investigation into patients with COVID-19 and ALF can lead to enhanced treatment regimens and risk stratification tools, which can ultimately improve mortality rates during these arduous times.

Twitter James Robert Pellegrini Jr. @jaypelly

Contributors JRP (guarantor, data acquisition, drafting of manuscript, critical revision of the manuscript for important intellectual content). BS (study concept and design). JR (data acquisition, drafting of manuscript). RFM (data acquisition, drafting of manuscript, critical revision of the manuscript for important intellectual content). DM (study concept and design, data acquisition, drafting of manuscript). NS (data acquisition). AG (data acquisition, drafting of manuscript). SM (statistical analysis, critical revision of the manuscript for important intellectual content). ES (statistical analysis, critical revision of the manuscript for important intellectual content). JA (study supervision).

Funding The authors have not declared a specific grant for this research from any funding agency in the public, commercial or not-for-profit sectors.

Competing interests None declared.

Patient consent for publication Not applicable.

Provenance and peer review Not commissioned; externally peer reviewed.

Data availability statement All data relevant to the study are included in the article or uploaded as online supplemental information. All patient information cannot be shared as this would violate HIPAA.
Open access This is an open access article distributed in accordance with the Creative Commons Attribution Non Commercial (CC BY-NC 4.0) license, which permits others to distribute, remix, adapt, build upon this work non-commercially, and license their derivative works on different terms, provided the original work is properly cited, appropriate credit is given, any changes made indicated, and the use is non-commercial. See: http://creativecommons.org/licenses/by-nc/4.0/.

\section{ORCID iDs}

James Robert Pellegrini Jr. http://orcid.org/0000-0002-6317-3000

Jose R Russe-Russe http://orcid.org/0000-0001-7801-2165

Daniel Meshoyrer http://orcid.org/0000-0003-0003-5425

\section{REFERENCES}

1 "COVID-19 United States Cases by County." Johns Hopkins Coronavirus Resource Center. coronavirus.jhu.edu/us-map.

2 Bolger T. "First Coronavirus Case on Long Island Confirmed in Nassau.". LI Press 2020;9 www.longislandpress.com/2020/03/05/ first-coronavirus-case-on-long-island-confirmed-in-nassau/

3 McMichael TM, Currie DW, Clark S, et al. Epidemiology of COVID-19 in a long-term care facility in King County, Washington. New England Journal of Medicine 2020;382:2005-11. www.nejm.org/doi/full/10. 1056/NEJMoa2005412?query=featured_coronavirus.

4 Ostermann M, Lumlertgul N, Forni LG, et al. What every intensivist should know about COVID-19 associated acute kidney injury. J Crit Care 2020;60:91-5.

5 Fan Z, Chen L, Li J, et al. Clinical features of COVID-19-Related liver functional abnormality. Clin Gastroenterol Hepatol 2020;18:1561-6.

6 Stravitz RT, Lee WM. Acute liver failure. Lancet 2019;394:869-81.

7 Arroyo V, Jalan R. Acute-On-Chronic liver failure: definition, diagnosis, and clinical characteristics. Semin Liver Dis 2016;36:109-16.

8 Zhang Y, Zheng L, Liu L, et al. Liver impairment in COVID-19 patients: a retrospective analysis of 115 cases from a single centre in Wuhan City, China. Liver Int 2020;40:2095-103.

9 Mao R, Qiu Y, He J-S, et al. Manifestations and prognosis of gastrointestinal and liver involvement in patients with COVID-19: a systematic review and meta-analysis. Lancet Gastroenterol Hepatol 2020;5:667-78.

10 Mandal A, Konala VM, Adapa S, et al. Gastrointestinal manifestations in COVID-19 infection and its practical applications. Cureus 2020;12:e8750.

11 Perico L, Benigni A, Casiraghi F, et al. Immunity, endothelial injury and complement-induced coagulopathy in COVID-19. Nat Rev Nephrol 2021;17:46-64.

12 Ziegler CGK, Allon SJ, Nyquist SK, et al. SARS-CoV-2 receptor ACE2 is an interferon-stimulated gene in human airway epithelial cells and is detected in specific cell subsets across tissues. Cell 2020;181:1016-35

13 Saviano A, Wrensch F, Ghany MG. Liver disease and COVID-19: from pathogenesis to clinical care. Hepatology 2020.

14 Machhi J, Herskovitz J, Senan AM, et al. The natural history, pathobiology, and clinical manifestations of SARS-CoV-2 infections. $J$ Neuroimmune Pharmacol 2020;15:359-86.

15 Garrido I, Liberal R, Macedo G. Review article: COVID-19 and liver disease-what we know on 1stMay 2020. Aliment Pharmacol Ther 2020:1-9.

16 Pirola CJ, Sookoian S. COVID-19 and ACE2 in the liver and gastrointestinal tract: putative biological explanations of sexual dimorphism. Gastroenterology 2020;159:1620-1.

17 Xu Z, Shi L, Wang Y, et al. Pathological findings of COVID-19 associated with acute respiratory distress syndrome. Lancet Respir Med 2020;8:420-2.

18 Paizis G, Tikellis C, Cooper ME, et al. Chronic liver injury in rats and humans upregulates the novel enzyme angiotensin converting enzyme 2. Gut 2005;54:1790-6.

19 Chai X, Hu L, Zhang Y. Specific ACE2 expression in cholangiocytes may cause liver damage after 2019-nCoV infection. Cold Spring Harbor, NY: Cold Spring Harbor Laboratory, 2020.

20 Zhou Y, Fu B, Zheng X, et al. Pathogenic T-cells and inflammatory monocytes incite inflammatory storms in severe COVID-19 patients. Natl Sci Rev 2020;7:998-1002.

21 Kleiner DE. Liver biopsy shines a light on COVID-19-Related liver injury. Cell Mol Gastroenterol Hepatol 2021;11:881-2.

22 Ray A, Jain D, Goel A. Clinico-pathological features in fatal COVID-19 infection: a preliminary experience of a tertiary care center in North India using postmortem minimally invasive tissue sampling. Expert review of respiratory medicine. 